\title{
Quantification and Identification of Bioactive Eugenol in Myristica fragrans Seed Using Validated High Performance Thin Layer Chromatography Technique
}

\author{
Mohamad Taleuzzamana ${ }^{1}$, Asadullah Jahangirb ${ }^{2}$ and Sadaf Jamal Gilania ${ }^{1 *}$ \\ ${ }^{1}$ Department of Pharmaceutical Chemistry, Glocal School of Pharmacy, Glocal University, Saharanpur 247121, Uttar Pradesh, India \\ ${ }^{2}$ Department of Pharmaceutics, Glocal School of Pharmacy, Glocal University, Saharanpur 247121, Uttar Pradesh, India
}

${ }^{*}$ Corresponding author: Dr. Sadaf Jamal Gilani, Associate Professor, Department of Pharmaceutical Chemistry, Glocal School of Pharmacy, Glocal University, Saharanpur 247121 (UP), India, Tel: +91-9997939221; E-mail: gilanisadaf@gmail.com

Received date: Sep 11, 2017; Accepted date: Oct 03, 2017; Published date: Oct 09, 2017

Copyright: ( 2017 Taleuzzamana M. This is an open-access article distributed under the terms of the Creative Commons Attribution License, which permits unrestricted use, distribution, and reproduction in any medium, provided the original author and source are credited.

\begin{abstract}
A sensitive, selective, precise and stability indicating high-performance thin layer chromatographic method (HPTLC) was developed and validated for analysis of eugenol from methanolic extract of Myristica fragrans seed. The chromatography study was performed on aluminium foil-backed silica gel 60 F-254 HPTLC plates using toluene-ethyl acetate-formic acid $(2: 5: 0.2, \mathrm{v} / \mathrm{v} / \mathrm{v})$ as the mobile phase. The densitometric determination was carried out by TLC scanner (CAMAG) at $560 \mathrm{~nm}$ in reflectance/absorbance mode. The developed method was validated for different parameters like linearity, precision, recovery, robustness, detection limits, quantification limits and stressed stability study in accordance with $\mathrm{ICH}$ guidelines. The developed analytical method were found to be linear in the concentration range of $100-1000 \mathrm{ng}$ band $^{-1}$ with regression value closer to unity $(\mathrm{r} 2=0.998)$. The developed system was found to give compact spots for eugenol (Rf 0.55) with the limit of detection and limit of quantification (21 and 63 $\mathrm{ng}$ band $^{-1}$ ) respectively. Further the study showed recovery of eugenol in the range of $99.3-99.8 \%$ with the precision value $\leq 1.85 \%$ and $\leq 1.71 \%$. The all validation parameters result showed satisfactory result in comparison to pure eugenol. The stress degradation study of eugenol showed well separated degraded peak from the pure eugenol. This developed stability indicating HPTLC method was found to ideal method to separate the eugenol from its degradation products. Further this method will be successfully used in the analysis and routine quality control of eugenol loaded formulations.
\end{abstract}

Keywords: Myristica fragrans, Eugenol; HPTLC; Validation; Stress degradation; Recovery; Robustness

\section{Introduction}

Nowadays various medicinal herbs have got much attention by the researchers and opened up a wide area of research in applying it as a medicine to cure various diseases. Eugenol belongs to a chemical class of phenylpropanoids (C10H12O2) with IUPAC name 4-Allyl-2methoxy phenol having molecular mass $164.2 \mathrm{~g} / \mathrm{mol}$. (Figure 1). It is partially soluble in water and its solubility increases with the addition of organic solvents. The color of the compound ranges from clear to pale yellow [1,2]. It is isolated from the different plant like Myristica fragrans, Eugenia caryophyllata, Cinnamomum tamala, Zygium aromaticum, Ocimum basilicum, Ocimum grattisimum, Ocimum tenuiflorum, Pimenta racemosa etc. Among these plant the maximum content of eugenol can be obtained from Eugenia caryophyllata, It is the principal source of clove oil which contains $45-90 \%$ eugenol as its constituent [1,3,4]. Eugenol, the principal component of Myristica fragrans seed extract is known to have several pharmacological properties [5-10]. This versatile bioactive compound is a key ingredient used in the production of perfumes, cosmetics, flavorings agents, culinary purposes and further therapeutically used in the treatment of a toothache.

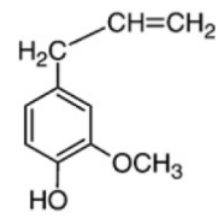

Figure 1: Chemical structure of eugenol.

HPTLC technique is becoming a routine analytical for the number of herbal as well as synthetic drugs. The wide acceptance of this method due to low sample needed for scaleup, low operating cost, high sample throughput, several samples can be run simultaneously, small volume of mobile phase needed lead to lower cost and analysis time [11-12]. This technique are commonly applied for the purity testing, identification, quantification, and stability testing of raw materials and developed formulation (pharmaceuticals, cosmetics, nutrients) [13-16]. Due to several advantages of HPTLC, it has gained widespread interest as a favorable technique for the identification and quantification of pharmacologically bioactive compounds from the raw material of plants (leaves, seed, and flowers) and herbal formulations. Further, high-performance thin layer chromatography (HPTLC) has been widely employed for the quantification of secondary metabolites [17-18]. So, the aim of present study is to develop and validate a rapid, sensitive, robust, effective and economical 
HPTLC method for the estimation of eugenol to optimize the new solvent system. A special attention was paid to the determination and separation of eugenol from its degradation metabolites by predicting its stability in different stress conditions $[19,20]$.

\section{Material and Methods}

\section{Materials}

Standard eugenol was purchased from Sigma Aldrich, Mumbai, India. Mature seed powder of Myristica fragrans were purchased from Sunpure extarct privale Ltd. (Delhi) for extraction purpose. Precoated silica gel 60 F254 HPTLC plates were purchased from E. Merck, Germany. All the solvents used were of chromatography grade and other chemicals used were of analytical reagent (AR) grade.

\section{Methods}

HPTLC instrumentation and condition: The analysis was performed with precoated silica gel aluminium plate $60 \mathrm{~F}-254,(20 \mathrm{~cm} \times 10 \mathrm{~cm}$ with $250 \mu \mathrm{m}$ thickness; E. Merck, Darmstadt, Germany, Anchrom Technologists, Mumbai). The prewashed plates were activated at $60^{\circ} \mathrm{C}$ for $5 \mathrm{~min}$ prior to the study. A constant sample application was done by using Camag microlitre syringe with the rate of $160 \mathrm{~nL} \mathrm{~s}-1$. The space between two bands was $6 \mathrm{~mm}$ maintained with slit dimension was kept at $5 \mathrm{~mm} \times 0.45 \mathrm{~mm}$. the scanning speed was $20 \mathrm{~mm} / \mathrm{s}$ maintained and each track was scanned thrice. The optimized mobile phase composition $(20 \mathrm{~mL})$ consisted toluene/ethyl acetate/formic acid $(2: 5: 0.2, \mathrm{v} / \mathrm{v})$ was used for the analysis. The linear ascending process was performed in $20 \times 10 \mathrm{~cm}$ twin trough pre-saturated glass chamber (Camag, Muttenz, Switzerland). To get high resolution HPTLC plate development was carried out for twice with the mobile phase. The chamber saturation was performed for $30 \mathrm{~min}$ at room temperature $\left(25 \pm 2^{\circ} \mathrm{C}\right)$ at the relative humidity of $60 \pm 5 \%$ with the mobile phase. Camag TLC scanner III was used to perform densitometric scanning in the reflectance-absorbance mode at $560 \mathrm{~nm}$ and operated by WinCATS software (Version 1.2.0). The deuterium lamp as source of radiation emitting a continuous UV spectrum between 200 and 400 $\mathrm{nm}$ and the concentrations of the compounds were quantified from the intensity of diffusely reflected light.

Preparation of standard and quality control (QC) samples: The standard stock solutions of eugenol $(10 \mathrm{mg} / \mathrm{mL})$ were prepared in methanol, and further dilutions were done to get solutions in the concentration range of 0.1 to $1.0 \mathrm{mg} / \mathrm{mL}$. The calibaration plot of eugenol standard were prepared with concentration range $1-10 \mu \mathrm{L}$, to get the concentration range 100-1000 ng band ${ }^{-1}$ for the application on HPTLC plate. The peak area and concentration were applied to plot the calibaration plot and their regression equation were calculted by linear least-squares method. The study was performed with application of each amount in triplicate. The QC samples used for the validation study in three different concentrations as low, medium and high at level of 150, 300 and $600 \mathrm{ng}^{\text {band }}{ }^{-1}$.

Extraction process: The seed powder of Myristica fragrans was packed in a muslin cloth and kept in a methanol containing beaker for $72 \mathrm{~h}$ with continuous shaking. The methanolic extracts were collected, filtered and the resultant filtrates were concentrated under reduced pressure using rotary evaporator. The protocol used for preparing sample solutions was optimized for high quality fingerprinting. Methanol has been used as extraction solvent due to the high solubility of eugenol. The fingerprinting of methanolic extracts of eugenol was executed by spotting $10 \mu \mathrm{L}$ of test sample solution on a HPTLC plate and the plates were developed $(n=6)$ and scanned as same discussed above.

Method validation: Validation of the developed method has been carried out as per ICH guidelines for linearity range, precision, accuracy as recovery, robustness, limits of detection (LOD), limits of quantification (LOQ) and stability study [21-25].

Precision and accuracy: Both interday and intraday precision of the method was evaluated by performing replicate analyses $(n=6)$ of QC samples at low, medium and high levels of 150, 300, $600 \mathrm{ng}$ band -1 . The interday precision study was done by repeating the study on same day whereas in intraday assay the same study was repeated for three different days. The result of precision was expressed as the coefficient of variation $(\mathrm{CV}, \%)$ of measured concentrations for each calibration level whereas accuracy was expressed as percentage recovery.

Accuracy, as recovery: The accuracy was determined by standard additions method at three different levels, i.e. by multiple level recovery studies. The recovery studies were performed with extra 50, 100 and $150 \%$ level from the initial level [21]. It was performed by application of test sample $(n=6)$ of known concentrations of eugenol that had been prepared from stock solutions. The percent recovery was calculated using regression equation at different levels in the sample.

Limit of detection (LOD) and quantification (LOQ): The limit of detection is defined as the lowest amount of analyte detected in a sample that cannot be quantitated as an exact concentration whereas the limit of quantification is the lowest amount of analyte in a sample that can be quantitatively determined with suitable precision and accuracy. The limits of detection (LOD) and quantification (LOQ), was calculated using the formula as $\mathrm{k} \sigma / \mathrm{b}$ where $\mathrm{k}=3$ for LOD and 10 for LOQ, $\sigma$ is the standard deviation of the intercept and $b$ is the slope of the calibration curve [22-24].

Robustness: Robustness was studied in triplicate at $300 \mathrm{ng} \mathrm{band}^{-1}$ by making small changes to different parameters like mobile phase composition, mobile phase saturation time, and mobile phase volume. The effects of robustness were examined on the results of peak areas and $\mathrm{Rf}$ value. The mobile phase prepared from toluene/ethyl acetate/ formic acid in different proportions (2.25:4.75:0.2 and 1.75:5.25:0.2, $\mathrm{v} / \mathrm{v})$ were used for chromatography. The mobile phase volume $(13,17$ and $15 \mathrm{ml}$ ) and saturation time (10,20 and $30 \mathrm{~min})$ were used for the study respectively. Further, the plates were prewashed with methanol and activated for different time intervals 2,5 and 7 minutes at $60 \pm 5^{\circ} \mathrm{C}$ [24].

Stability studies: The stress testing of the drug substance can help identify the likely degradation products, the stability of the molecule and also validate the stability and specificity of the analytical procedures [25]. The degradation studies were carried out as per by subjecting the standard eugenol sample to oxidation, wet heat, dry heat and photo-degradation to evaluate the stability indicating properties of the developed HPTLC method [22-24].

Hydrogen peroxide-induced degradation: To $25 \mathrm{ml}$ of a methanolic stock solution of eugenol, $10 \mathrm{ml}$ of $50 \% \mathrm{w} / \mathrm{v}$ hydrogen peroxide were added. The solution was heated in boiling water bath for $15 \mathrm{~min}$ to remove completely the excess of hydrogen peroxide and then refluxed for $2 \mathrm{~h}$ at $70^{\circ} \mathrm{C}$. The resultant solution $\left(200 \mathrm{ng} \mathrm{band}^{-1}\right)$ was applied on TLC plate and the chromatograms were run for the analysis as described above. 
Citation: Taleuzzamana M, Jahangir A and Gilania SJ (2017) Quantification and Identification of Bioactive Eugenol in Myristica fragrans Seed Using Validated High Performance Thin Layer Chromatography Technique. Pharm Anal Acta 8: 563. doi:10.4172/2153-2435.1000563

Page 3 of 6

Dry heat and wet heat degradation: The standard drug was placed in the oven at $100^{\circ} \mathrm{C}$ for 7 days to study dry heat degradation, and the stock solution was refluxed for $12 \mathrm{~h}$ on boiling water bath for wet heat degradation. The resultant solution (200 ng band $\left.{ }^{-1}\right)$ was applied on TLC plate. Further, the HPTLC study was performed and the chromatograms were run for the analysis.

Photochemical and UV degradation: The photochemical stability of the eugenol was also studied by exposing the stock solution $(250 \mu \mathrm{g}$ ml-1) to direct sunlight for 3 days on a wooden plank and kept on the terrace. The eugenol solution was also exposed to UV radiation for 15 days in UV stability chamber. One microlitre (200 ng band $\left.{ }^{-1}\right)$ from each sample was applied on TLC plate and chromatograms were run as described above.

\section{Results and Discussion}

\section{Mobile phase optimization}

There are different solvent systems were tried for the separation of eugenol on the TLC plates. Initially, toluene: methanol: ethyl acetate: formic acid used as the solvent system to get a high-resolution peak. To decrease the spot to the middle and get better peak resolution methanol was removed from the mobile phase system and the optimized composition was selected as toluene: ethyl acetate: formic acid (2:5:0.2, v/v/v) with $\mathrm{Rf}$ value of 0.55 (Figure 2). The high resolution between spots of standard and depredates achieved due to the use of methanol pretreated TLC plates. Prior to application the plates were activated at $60^{\circ} \mathrm{C}$ for $30 \mathrm{~min}$, and further saturated with conc. ammonia vapors for $30 \mathrm{~min}$ in TLC chamber. The edge effect has been eliminated to avoid unequal solvent evaporation from the developing plate that may lead to random behavior usually resulting lack of $\mathrm{Rf}$ value reproducibility. So the attempt has been taken to develop and validate a simple, robust, and cost effective HPTLC technique to quantify eugenol in the methanolic extract of Myristica fragrans seed. The methanolic extract peak of eugenol was well resolved at Rf value 0.55 depicted in Figure 3. The developed method was found to be quite selective with good baseline resolution of each compound.

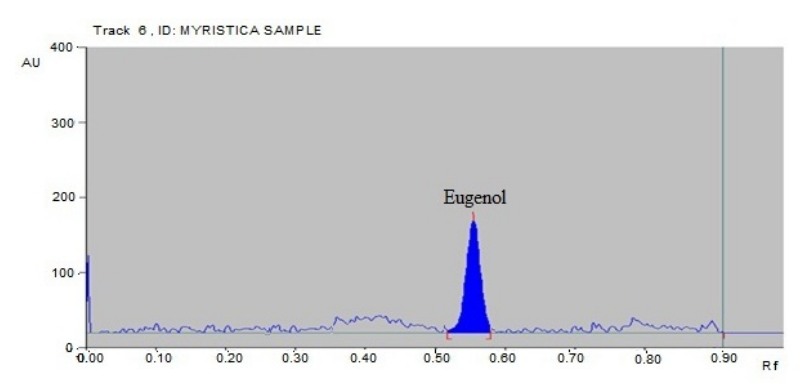

Figure 2: HPTLC chromatogram of standard eugenol at RF 0.55

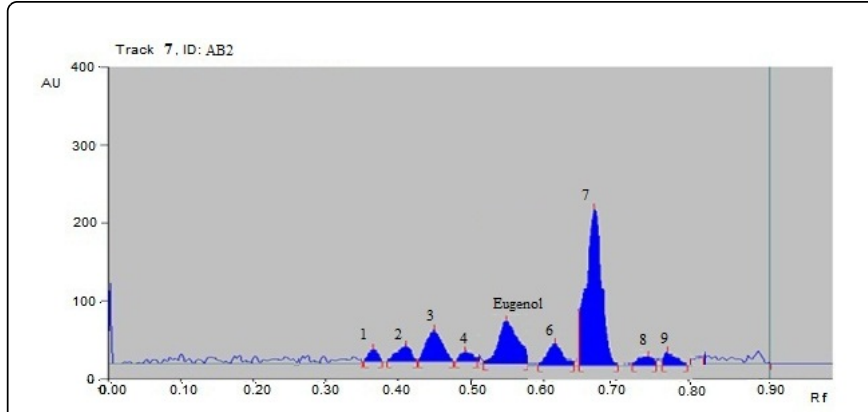

Figure 3: HPTLC chromatogram of methanolic extract of Myristica fragrans scanned at $560 \mathrm{~nm}$ [peak 1-9; eugenol (0.55)].

\section{Method validation}

Linearity: The linearity plot of eugenol was validated by taking the six-point calibration curves for the compound in the range of 100-1000 ng band ${ }^{-1}$. The linear regression equation and the correlation coefficient are depicted in Table 1. The compound showed a good linearity response for the developed method in above concentration. The mean values of the slope were found to be $0.0068 \pm 0.0007$. Each point was taken in triplicate to give the analyses of each concentration to establish the calibration curve. The LOD and LOQ value of the developed method for eugenol were found to be 21 and $63 \mathrm{ng} \mathrm{band}^{-1}$ which showed that the method was sensitive to detect and quantify [22].

\begin{tabular}{|l|l|}
\hline Parameter & Values \\
\hline $\mathrm{R}_{\mathrm{F}}$ & 0.55 \\
\hline Linearity range $\left(\mathrm{ng} \mathrm{band}^{-1}\right)$ & $100-1000$ \\
\hline Regression equation & $\mathrm{Y}=4.930 \mathrm{x}-8.432$ \\
\hline Correlation coefficient $\left(\mathrm{r}^{2}\right)$ & 0.998 \\
\hline Slope $\pm \mathrm{SD}$ & $0.0068 \pm 0.0007$ \\
\hline Intercept $\pm \mathrm{SD}$ & 9.28 \\
\hline
\end{tabular}

Table 1: Linear regression analysis data for the developed HPTLC method of Eugenol.

Precision and accuracy: The intraday and interday precision were expressed as \% recovery of the eugenol at three different level (150, 300 and $600 \mathrm{ng}$ band $^{-1}$ ) were shown in Table 2 . The percentage recovery was found to be in the range of $98.9-100.2 \%$ and 97.9-99.7, Standard deviation-0.35-0.38 \& $0.59-0.60, \%$ CV-0.23-0.06 \& $0.40-0.10$ respectively for intraday batch and Inter batch. Indicates the method was accurate by satisfying the acceptance criteria. Further, the accuracy of the eugenol was found to be in the range of 99.3 to $99.8 \%$ and the $\%$ RSD, SD and Precision Value found to be less than 2, which demonstrated the good precision of proposed method (Table 3). These values are within the acceptable range, so the method was accurate and precise, reliable, and reproducible [22]. 
Citation: Taleuzzamana M, Jahangir A and Gilania SJ (2017) Quantification and Identification of Bioactive Eugenol in Myristica fragrans Seed Using Validated High Performance Thin Layer Chromatography Technique. Pharm Anal Acta 8: 563. doi:10.4172/2153-2435.1000563

Page 4 of 6

\begin{tabular}{|c|c|c|c|c|c|c|c|c|c|c|c|}
\hline \multirow{2}{*}{$\begin{array}{l}\text { Nominal } \\
\text { band-1) }\end{array}$} & \multirow[t]{2}{*}{ concentratio(ng } & \multicolumn{5}{|l|}{ Intraday batch } & \multicolumn{5}{|l|}{ Inter day batch } \\
\hline & & $\begin{array}{l}\text { Obtained } \\
\text { Concentration }\end{array}$ & $\begin{array}{l}\text { Precisio } \\
\mathrm{n}\end{array}$ & \% Recovery & S.D. & $\% \mathrm{CV}$ & $\begin{array}{l}\text { Obtained } \\
\text { Concentration }\end{array}$ & $\begin{array}{l}\text { Precisio } \\
\mathrm{n}\end{array}$ & $\%$ Recovery & S.D. & $\% \mathrm{CV}$ \\
\hline 150 & & 148.4 & 1.85 & 98.9 & 0.35 & 0.23 & 146.8 & 1.63 & 97.9 & 0.59 & 0.4 \\
\hline 300 & & 297.8 & 1.72 & 99.2 & 0.64 & 0.21 & 295.4 & 1.71 & 98.5 & 0.38 & 0.12 \\
\hline 600 & & 601.5 & 1.55 & 100.2 & 0.38 & 0.06 & 598.2 & 1.56 & 99.7 & 0.6 & 0.1 \\
\hline
\end{tabular}

Table 2: Intraday and Inter-day precision data of the eugenol.

\begin{tabular}{|c|c|c|c|c|c|c|c|}
\hline $\begin{array}{l}\text { Conc. added to analyte } \\
(\%)\end{array}$ & Theoretical (ng) & Added (ng) & Detected (ng) & Recovery (\%) & RSD (\%) & SD & Precision \\
\hline 50 & \multirow[t]{3}{*}{300} & 200 & 496.4 & 99.3 & 1.85 & 0.21 & 0.64 \\
\hline 100 & & 400 & 697.6 & 99.6 & 1.48 & 0.40 & 0.14 \\
\hline 150 & & 600 & 898.6 & 99.8 & 1.46 & 0.61 & 0.17 \\
\hline
\end{tabular}

Table 3: Accuracy data of the eugenol $(n=6)$.

Robustness: The robustness value for the above developed method was shown in Table 4 and their area with SD and \% RSD was calculated. The different parameters used for the study were variation in mobile phase ratio, mobile phase volume, saturation time and activation time of prewashed-TLC plates at concentration levels of 300 ng band ${ }^{-1}$ (in triplicate). The result of the study showed that the small deliberate change in the chromatographic condition gives no significant effect on the area and Rf value. The low values of \% RSD (less than 2\%) indicated the robustness of the developed method.

\begin{tabular}{|c|c|c|c|c|c|c|c|}
\hline \multicolumn{8}{|c|}{ Mobile Phase } \\
\hline \multirow{2}{*}{$\begin{array}{l}\text { Conc. } \\
\mathrm{ng} / \mathrm{ml}\end{array}$} & \multicolumn{2}{|c|}{ Toulene: Ethyl acetate: formic acid (v/v) } & \multicolumn{5}{|l|}{ Results } \\
\hline & Original & Used & Area \pm SD & \%RSD & $\mathbf{R f}$ & & \\
\hline \multirow[b]{3}{*}{300} & \multirow[b]{3}{*}{$2: 5: 0.2$} & $2.25: 4.75: 0.2$ & \multicolumn{3}{|l|}{$576 \pm 23$} & 0.6 & 0.53 \\
\hline & & 2:5:0.2 & $572 \pm 18$ & 0.61 & 0.55 & & \\
\hline & & $1.75: 5.25: 0.2$ & $569 \pm 20$ & 0.62 & 0.56 & & \\
\hline & \multicolumn{7}{|c|}{ Mobile Phase Volume (15 $\pm 2 \mathrm{ml})$} \\
\hline \multirow{3}{*}{$\begin{array}{l}\text { Conc. } \\
\mathrm{ng} / \mathrm{ml}\end{array}$} & \multirow[b]{2}{*}{ Volume (ml) } & \multicolumn{6}{|l|}{ Result } \\
\hline & & Area \pm SD & \%RSD & & Rf & & \\
\hline & 17 & $570 \pm 23$ & & 0.57 & & 0.54 & \\
\hline \multirow[t]{3}{*}{300} & 15 & $574 \pm 18$ & & 0.59 & & 0.55 & \\
\hline & 13 & $568 \pm 20$ & & 0.58 & & 0.53 & \\
\hline & \multicolumn{7}{|c|}{ Duration of Saturation } \\
\hline \multirow{3}{*}{$\begin{array}{l}\text { Conc. } \\
\mathrm{ng} / \mathrm{ml}\end{array}$} & \multirow{2}{*}{$\begin{array}{l}\text { Time } \\
(\min )\end{array}$} & \multicolumn{6}{|l|}{ Result } \\
\hline & & Area \pm SD & \%RSD & & $\mathbf{R f}$ & & \\
\hline & 10 & $571 \pm 23$ & & 0.58 & & 0.54 & \\
\hline \multirow[t]{3}{*}{300} & 20 & $574 \pm 18$ & & 0.59 & & 0.55 & \\
\hline & 30 & $567 \pm 20$ & & 0.6 & & 0.53 & \\
\hline & \multicolumn{7}{|c|}{ Activated at $60 \pm 5^{\circ} \mathrm{C}$} \\
\hline
\end{tabular}


Citation: Taleuzzamana M, Jahangir A and Gilania SJ (2017) Quantification and Identification of Bioactive Eugenol in Myristica fragrans Seed Using Validated High Performance Thin Layer Chromatography Technique. Pharm Anal Acta 8: 563. doi:10.4172/2153-2435.1000563

Page 5 of 6

\begin{tabular}{|l|l|l|l|l|l|l|}
\hline $\begin{array}{l}\text { Conc. } \\
\text { ng/ml }\end{array}$ & $\begin{array}{l}\text { Time } \\
(\mathrm{min})\end{array}$ & Area \pm SD & \%RSD & & Rf & \\
\hline & 2 & $572 \pm 23$ & 0.63 & & 0.54 \\
\cline { 2 - 7 } & 5 & $576 \pm 18$ & 0.61 & & 0.55 & \\
\hline \multirow{2}{*}{300} & 7 & $573 \pm 20$ & 0.6 & & 0.53 & \\
\hline
\end{tabular}

Table 4: Robustness of the developed HPTLC method of eugenol $(n=6)$.

Stability studies: The results of the forced degradation study of eugenol using are summarized in Table 5.

\begin{tabular}{|l|l|l|}
\hline Degradation condition & $\begin{array}{l}\text { No. of degradation } \\
\text { products }\end{array}$ & Rf value \\
\hline Peroxide-induced degradation & 2 & $0.30,0.36$ \\
\hline Dry heat-wet heat $\left(100^{\circ} \mathrm{C}\right)$ & 5 & $0.49,0.63,0.68$ \\
\hline Photochemical degradation & 1 & 0.43 \\
\hline UV degradation & 1 & 0.39 \\
\hline
\end{tabular}

Table 5: Stress induced stability studies data for the developed method.

Hydrogen peroxide-induced degradation: The sample degraded with $50 \% \mathrm{w} / \mathrm{v}$ hydrogen peroxide showed additional peaks at $\mathrm{Rf}$ value of 0.30 and 0.36 . The spots of degraded products were well resolved from the parent compound spot.

Dry heat and wet heat degradation: The samples degraded under dry heat and wet heat conditions (Figure 4) showed additional peaks at Rf values of $0.49,0.63$, and 0.68 respectively. The spots of degraded products were well resolved from the parent compound spot.

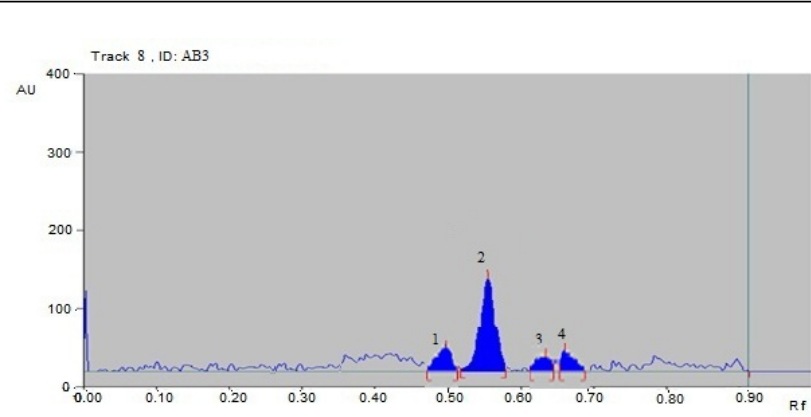

Figure 4: Chromatogram of dry heat degraded eugenol (peak 1: degraded, Rf: 0.49 , peak 2: eugenol, Rf: 0.55 , peak 3: degraded, Rf: 0.63 , peak 4: degraded, Rf: 0.68 )

Photochemical and UV degradation: The photo degraded sample showed one additional peak at $\mathrm{Rf}$ value of 0.43 when eugenol solution was left in daylight for 3 days. The eugenol was degraded when exposed to UV irradiation for 15 days and showed additional peaks at $\mathrm{Rf}$ value of 0.39 . The spot of UV degraded product was well resolved from the standard.

\section{Conclusion}

The developed HPTLC method used for the estimation of eugenol in pure as well as extracted product from Myristica fragrans using toulene: ethyl acetate: formic acid (v/v) combination as the mobile phase showed good chromatographic separation. The developed method was validated for linearity, precision, accuracy; robustness and stressed stability were found to be simple, robust and effective for quality control as well as routine analysis of eugenol in pharmaceutical dosage forms. The standard deviation and \%CV for Intraday and Interday found $0.35-0.38 \& 0.59-0.60$, and $0.23-0.06$ and $0.40-0.10$ respectively. Which indicates the method was accurate by satisfying the acceptance criteria. Further, the accuracy of the eugenol was found to be less than 2 . The developed method showed linearity over the concentration range of $100-1000 \mathrm{ng}^{\text {band }}{ }^{-1}$ tested. This method was found to be economical due to lower solvent consumption. Further the present developed method clearly proves usefulness in the detection of bioactive eugenol in methanolic extracts of Myristica fragrans. Thus, it could be concluded that the developed HPTLC method is found to be simple, rapid and robust for routine analysis of pure eugenol.

\section{Acknowledgements}

Thanks to Mr Manish (Sunpure Extract Pvt. Ltd. Delhi) for providing the herbal sample for the analysis study.

\section{References}

1. Sudarma IM, Ulfa M, Sarkono (2009) Chemical transformation of eugenol isolated from clove oil to 4-allyl-2-methoxy-6-sulfonicphenol and 4-allyl-2-methoxy-6-aminophenol. Indo J Chem 9: 267-270.

2. Kar Mahapatra S, Chakraborty SP, Majumdar S, Bag BG, Roy S (2009) Eugenol protects nicotine-induced superoxide mediated oxidative damage in murine peritoneal macrophages in vitro. Eur J Pharmacol 623: 132-140.

3. Yogalakshmi B, Viswanathan P, Anuradha CV (2010) Investigation of antioxidant, anti-inflammatory and DNA-protective properties of eugenol in thioacetamide-induced liver injury in rats. Toxicol 268: 204-212.

4. Kar Mahapatra S, Bhattacharjee S, Chakraborty SP, Majumdar S, Roy S (2011) Alteration of immune functions and Th1/Th2 cytokine balance in nicotine-induced murine macrophages: immunomodulatory role of eugenol and N-acetylcysteine. Int Immunopharmacol 11: 485-495.

5. Mahapatra SK, Roy S2 (2014) Phytopharmacological approach of free radical scavenging and anti-oxidative potential of eugenol and Ocimum gratissimum Linn. Asian Pac J Trop Med 7S1: S391-397.

6. Slamenova D, Horváthova E, Wsólova L, Sramkova M, Navarova J (2009) Investigation of anti-oxidative, cytotoxic, DNA-damaging and DNAprotective effects of plant volatiles eugenol and borneol in human-derived HepG2, Caco-2 and VH10 cell lines. Mutat Res 677: 46-52.

7. Mahboub R, Memmou F (2015) Antioxidant activity and kinetics studies of eugenol and 6-bromoeugenol. Nat Prod Res 29: 966-971. 
Citation: Taleuzzamana M, Jahangir A and Gilania SJ (2017) Quantification and Identification of Bioactive Eugenol in Myristica fragrans Seed Using Validated High Performance Thin Layer Chromatography Technique. Pharm Anal Acta 8: 563. doi:10.4172/2153-2435.1000563

Page 6 of 6

8. Ali S, Prasad R, Mahmood A, Routray I, Shinkafi TS, et al. (2014) Eugenolrich Fraction of Syzygium aromaticum (Clove) Reverses Biochemical and Histopathological Changes in Liver Cirrhosis and Inhibits Hepatic Cell Proliferation. J Cancer Prev 19: 288-300.

9. Singh V, Panwar R (2014) In vivo antioxidative and neuroprotective effect of 4-Allyl-2-methoxyphenol against chlorpyrifos-induced neurotoxicity in rat brain. Mol Cell Biochem 388: 61-74.

10. Ali SM, Khan AA, Ahmed I, Musaddiq M, Ahmed KS (2005) Antimicrobial activities of eugenol and cinnamaldehyde against the human gastric pathogen Helicobacter pylori. Ann Clin Microbiol Antimicrob 4: 20-24.

11. Van Zyl RL, Seatlholo ST, van Vuuren SF, Viljoen AM (2006) The biological activities of 20 nature identical essential oil constituents. J Essent Oil Res 18:129-133.

12. Oyedemi SO, Okoh AI, Mabinya LV, Pirochenva G, Afolayan AJ (2009) The proposed mechanism of bactericidal action of eugenol, a $\alpha$-terpineol and $\gamma$-terpinene against Listeria monocytogenes, Streptococcus pyogenes, Proteus vulgaris and Escherichia coli. Afr J Biotechnol 8: 1280-1286.

13. Chaieb K, Zmantar T, Ksouri R, Hajlaoui H, Mahdouani K, et al. (2007) Antioxidant properties of the essential oil of Eugenia caryophyllata and its antifungal activity against a large number of clinical Candida species. Mycoses 50: 403-406.

14. Machado M, Dinis AM, Salgueiro L, Custódio JB, Cavaleiro C, et al. (2011) Anti-Giardia activity of Syzygium aromaticum essential oil and eugenol: effects on growth, viability, adherence and ultrastructure. Exp Parasitol 127: 732-739.

15. Neeraj K, Himani A, Bharat P, Abhijit K, Dhaneshwar SR (2005) Application of stability-indicating HPTLC method for quantitative determination of metadoxine in pharmaceutical dosage form. IL Farmaco 60: 351-360.

16. Faiyazuddin M, Ahmad N, Baboota S, Ali J, Ahmad S (2010) Chromatographic Analysis of trans and cis-Citral in Lemongrass Oil and in a Topical Phytonanocosmeceutical Formulation, and Validation of the Method. J Planar Chromatography 23: 233-236.
17. Biringanine G, Chiarelli MT, Faes M. Duez P (2006) A validation protocol for the HPTLC standardization of herbal products: Application to the determination of acteoside in leaves of Plantago palmata Hook. Talanta 69: 418-424.

18. Kpoviessia DSS, Gbaguidia F, Gbeenoua J, Accrombessia G, Moudachiroua M (2008) Validation of a method for the determination of sterols and triterpenes in the aerial part of Justicia anselliana (Nees) T. Anders by capillary gas chromatography. J Pharm Biomed Anal 48: 1127-1135.

19. Halinski P, Szafranek J, Szafranek BM, Goebiowski M, Stepnowski P (2009) Chromatographic fractionation and analysis of the main components of eggplant (Solanum melongena L.) leaf cuticular waxes. Acta Chromatographica 21: 127-137.

20. Anandjiwala S, Srinivasa H, Rajani M (2007) Isolation and TLC Densitometric Quantification of Gallicin, Gallic Acid, Lupeol and $\beta$ Sitosterol from Bergia suffruticosa, a Hitherto Unexplored Plant. Chromatographia 66: 725-734.

21. Ali S, Taleuzzaman M, Gilani SJ, Ahmed L Md, Hafeez A (2016) Quantitative estimation of Donepenzil hydrochloride tablet by HPLC. IJPC 06: 02.

22. Mohammad T. Zzaman, Sadaf J. Gilani, K. Nagarajan, Shadab A. Siddiqui (2012) HPLC Method Development and Validation for Pharmaceutical Analysis- A Review. Internationale Pharmaceutica Sciencia 2: 13-21.

23. Sai Bindu NH, Rubesh Kumar S, Duganath N, Devanna N (2013) Extraction and screening of trimyristin in the seeds of myristica fragnans and in poly herbal formulations by spectroscopic and chromatographic techniques. Int J Uni Pharm Bio Sci 2: 569-581.

24. Mittal A, Imam SS, Parmar S, Gilani SJ, Taleuzzaman M (2015) Design of Experiment based Optimized RP-HPLC Method for Simultaneous Estimation of Amlodipine and Valsartan in Bulk and Tablet Formulations. Austin J Anal Pharm Chem, 2: 2381-8913.

25. 21 ICH (Q2R1) (1995) Draft Guidelines on Validation of Analytical Procedures: Text and Methodology, IFPMA, Switzerland. 